\title{
Forage lipid concentration, fatty acid profile and lamb productivity
}

\author{
G.P. COSGROVE, C.B. ANDERSON, T.W. KNIGHT, N.J. ROBERTS and G.C. WAGHORN \\ AgResearch, Grasslands Research Centre, PB 11008, Palmerston North \\ gerald.cosgrove@agresearch.co.nz
}

\begin{abstract}
Increasing the total lipid concentration and modifying the fatty acid profile in forage may increase energy intake and productivity of animals and improve the attributes of meat and milk for human health. To predict the outcome of modifying these traits in ryegrass, 3 groups of weaned lambs ( $\mathrm{n}=15$ per treatment) grazed ryegrass $(4 \%$ total lipid) and received twice-daily oral doses of oil at 0,28 or $56 \mathrm{ml} /$ day. The oil consisted of a blend of $75 \%$ linseed oil (high in linolenic acid) and 25\% sunflower oil (high in linoleic acid). For the 2 groups receiving oil the total dietary lipid concentration was increased to simulate ryegrass having medium $(6 \%)$ or high $(8 \%)$ total lipid. Average daily liveweight gain ( $238 \mathrm{~g}$ /day) and carcass weight $(16.9 \mathrm{~kg})$ were not significantly affected by lipid concentration in the diet. However, lambs eating the simulated high-lipid ryegrass ate $16 \%$ less dry matter ( 1285 vs $1530 \mathrm{~g} / \mathrm{d}, \mathrm{P}=0.07$ ) but had 33\% higher feed conversion efficiency ( 85 vs $64 \mathrm{~g}$ carcass gain $/ \mathrm{kg}$ intake, $\mathrm{P}<0.05)$ than control lambs. Blood plasma and carcass meat from lambs given oils contained lower concentrations of short chain, saturated fatty acids and higher concentrations of poly-unsaturated fatty acids. These simulated changes to ryegrass indicate that modifying the lipid concentration and fatty acid profile in ryegrass could have a feed-sparing effect and improve the human-health attributes of meat from lambs finished during the spring.
\end{abstract}

Keywords: average daily liveweight gain, dry matter intake, feed conversion efficiency, forage lipid, ryegrass

\section{Introduction}

Manipulating the lipid composition of forage grasses may improve their nutritional value for animals and the nutritional characteristics of the animal products consumed by humans. Increasing the total lipid concentration in grass will increase its energy density and this should increase the productivity of grazing ruminants. Furthermore, the diet composition of animals affects the fatty acids in their milk and meat (Dewhurst et al. 2002). With the dependence on pasture-based systems for animal production in New Zealand, altering the lipid profile in grass may be the most economic way to change the fatty acid characteristics of the meat or milk produced by ruminants. These changes would be particularly beneficial if they increased the proportion of fatty acids having desirable attributes for human health such as conjugated linoleic acid (CLA, especially the cis-9, trans11 isomer), trans-vaccenic acid (TVA, trans-11 C18:1), and the long-chain omega-3 polyunsaturated fatty acids, and decreased the saturated short-chain fatty acids (C12:0, $\mathrm{C} 14: 0$ and $\mathrm{C} 16: 0)$ that can promote atherosclerosis (Ulbricht \& Southgate 1991). Conjugated linoleic acid reduces the severity of cancer in a number of animal models (Belury 1995; Kritchevsky 2000). Milk and meat from ruminants is the main source of TVA (Corl et al. 2001) and dietary TVA is known to be converted to CLA in situ in humans (Salminen et al. 1998). The longchain $\mathrm{n}-3$ polyunsaturated fatty acids (C20:5, C22:5 and C22:6) can reduce the potential for coronary heart disease, cancer, and arthritis (Simopoulos 1996).

Prior to embarking on long-term plant breeding projects to change these characteristics it is useful to first assess the potential to achieve the intended benefits. The merits of this target for forage improvement were tested in a proof-of-concept study designed to simulate the proposed changes to forage lipid total concentration and fatty acid profile. These effects were evaluated in terms of liveweight gain, feed conversion efficiency and carcass characteristics of lambs.

\section{Materials and methods}

\section{Animals and treatments}

Newly weaned lambs $(28.7 \pm 3.1 \mathrm{~kg})$ were randomly allocated to 3 treatment groups ( $\mathrm{n}=15$ lambs per group) and stocked on ryegrass for a finishing period of 52 days from 28 October to slaughter on 19 December. These lambs were brought to the yards twice daily (at 8:00 AM and 4:00 PM) and two groups received an oral dose (using a conventional drench gun) of a blend of $75 \%$ linseed and $25 \%$ sunflower oils to simulate the consumption of forage with $6 \%$ (medium, $\mathrm{M}$ ) and $8 \%$ (high, H) total lipids. The 3:1 blend of linseed oil (containing 51\% C18:3) and sunflower oil (69\% C18:2) was used to simulate the proposed increase in the proportions in ryegrass of linolenic (C18:3) and linoleic (C18:2) acids. The ryegrass contained 4\% total lipid (estimate from pre-trial samples analysed by near infrared reflectance spectroscopy (NIRS)) so $28 \mathrm{ml} /$ day and $56 \mathrm{ml} /$ day of oil was administered to each lamb in the M and $\mathrm{H}$ groups, respectively, in equal AM and PM doses. The third group of lambs (control, C) received oral doses of water $(28 \mathrm{ml} /$ day). The volume of oil dosed to reach the nominal dietary total lipid concentration for each 
treatment assumed a daily dry matter (DM) intake of $1400 \mathrm{~g} / \mathrm{hd} /$ day. Lambs were introduced to the dose progressively and the full dose rate was given from day 5 and remained at that rate throughout the trial.

\section{Pastures and stocking management}

All lambs grazed together as a single mob on hybrid ryegrass (Lolium perenne $x$ Lolium multiflorum $\mathrm{cv}$. Maverick Gold) pasture sown in the autumn, 6 months preceding the trial. Pasture was offered ad-libitum, and the lambs were shifted to a fresh allocation every 2 days.

\section{Measurements}

Daily herbage intake was estimated using n-alkane faecal markers over 6 days near the end of the 6-week trial period. Lambs were dosed twice daily (in conjunction with the oil) for 12 days with a tablet containing C32 alkane. After a 6-day equilibration period, faecal samples (rectal-grab) were taken for 6 consecutive days. The faecal samples were freeze-dried, bulked across days for each lamb on an equal dry weight basis and analysed to determine the concentration of C33 (plant) and C32 (dosed) alkanes. Samples of grass representing the herbage consumed by lambs were taken by hand-plucking twice during the faecal sampling period, freeze-dried and ground, and analysed to determine the concentrations of $\mathrm{C} 33$ and $\mathrm{C} 32$ alkanes. These samples, bulked together with samples taken by a similar method throughout the trial were also analysed by NIRS to estimate the concentration of soluble sugars, protein, neutral and acid detergent fibre, and organic matter digestibility and energy density.

The lambs were shorn at the start and end of the trial to determine wool production. They were weighed twice weekly immediately following the morning dosing. A blood sample was taken from each lamb on the day prior to slaughter at the AgResearch Ruakura abattoir. Carcasses were weighed and graded and samples of the $m$. longissimis thoracis muscle taken. The meat and blood plasma were analysed to determine the concentration of individual and total fatty acids ( $\mathrm{g} / \mathrm{g}$ total fatty acid in lean tissue, $\mu \mathrm{g}$ lipid/ml plasma). Extraction of fatty acids from the muscle and analysis by gas-liquid chromatography followed methods described by Knight et al. (2003) for beef. Data are presented for groups of fatty acids and selected individual fatty acids.

Feed conversion efficiency was calculated from pasture DM intake (g/day) and carcass gain (carcass weight minus initial live weight $\mathrm{x}$ assumed $40 \%$ dressing \%,g/day) and expressed as $g$ carcass gain $/ \mathrm{g}$ DM intake. For this calculation the mean daily DM intake measured over 6 days near the end of the trial was applied to the whole period.

\section{Statistical analysis}

Effects of treatment were compared by analysis of variance using SAS (SAS 1990) for liveweight gain, feed intake, wool growth and feed conversion efficiency and GENSTAT (GenStat 2000) for the concentration of total and individual fatty acids in plasma and meat. Adjusted means are presented with standard errors of difference (SED) for the comparison between treatments.

\section{Results}

\section{Ryegrass composition}

The mean composition $(\mathrm{g} / \mathrm{kg} \mathrm{DM})$ of the ryegrass during the trial was; lipids 44 , crude protein 260 , soluble sugars 110 , neutral detergent fibre 380 and acid detergent fibre 210. The organic matter digestibility was $840 \mathrm{~g} / \mathrm{kg}$ DM and energy density was $11.8 \mathrm{MJ} \mathrm{ME} / \mathrm{kg} \mathrm{DM}$.

\section{Liveweight gain and carcass weight and wool growth} The lambs dosed with oil at either the $\mathrm{M}$ or $\mathrm{H}$ level to simulate ryegrass with a modified lipid profile were similar to the control lambs (Table 1) in average daily liveweight gain (mean of all treatments $238 \mathrm{~g}$ /day), carcass weight $(16.9 \mathrm{~kg})$ and wool production $(16 \mathrm{~g} /$ day). Lambs maintained a consistent average daily gain throughout the trial (Figure 1).

Table 1 Adjusted means of average daily gain (g/day), DM intake (g/day) wool growth rate (g/day), carcass weight at slaughter $(\mathrm{kg})$ and efficiency of conversion of DM intake to carcass weight gain (g carcass gain/kg intake) of the Control group of lambs and the lambs receiving Medium (28 ml/day) or High (56 $\mathrm{ml} /$ day) doses of oil.

\begin{tabular}{|c|c|c|c|c|c|}
\hline & \multicolumn{3}{|c|}{ Treatment } & \multicolumn{2}{|c|}{ - Signif. } \\
\hline & Control & Medium & High & SED & $\mathrm{P}$ \\
\hline Average daily gain & 238 & 241 & 235 & 16.0 & NS \\
\hline DM intake & 1530 & 1450 & 1285 & 110.0 & 0.07 \\
\hline Wool growth rate & 16.5 & 15.9 & 16.7 & 0.68 & NS \\
\hline Carcass weight & 16.8 & 17.1 & 16.9 & 0.49 & NS \\
\hline Feed conversion efficiency & $64^{b}$ & $75^{\mathrm{ab}}$ & $85^{a}$ & 7.5 & * \\
\hline
\end{tabular}

NS not significant, ${ }^{*} \mathrm{P}<0.05$.

Treatment means with different letter superscripts are significantly different from each other. 
Figure 1 Cumulative liveweight gain of Control lambs ( 0 oil per day) and lambs receiving Medium ( $28 \mathrm{ml} /$ day) and High ( $56 \mathrm{ml} /$ day) doses of oil, over 52 days from the start of dosing until slaughter (for statistical comparison of treatment effects see Table 1).

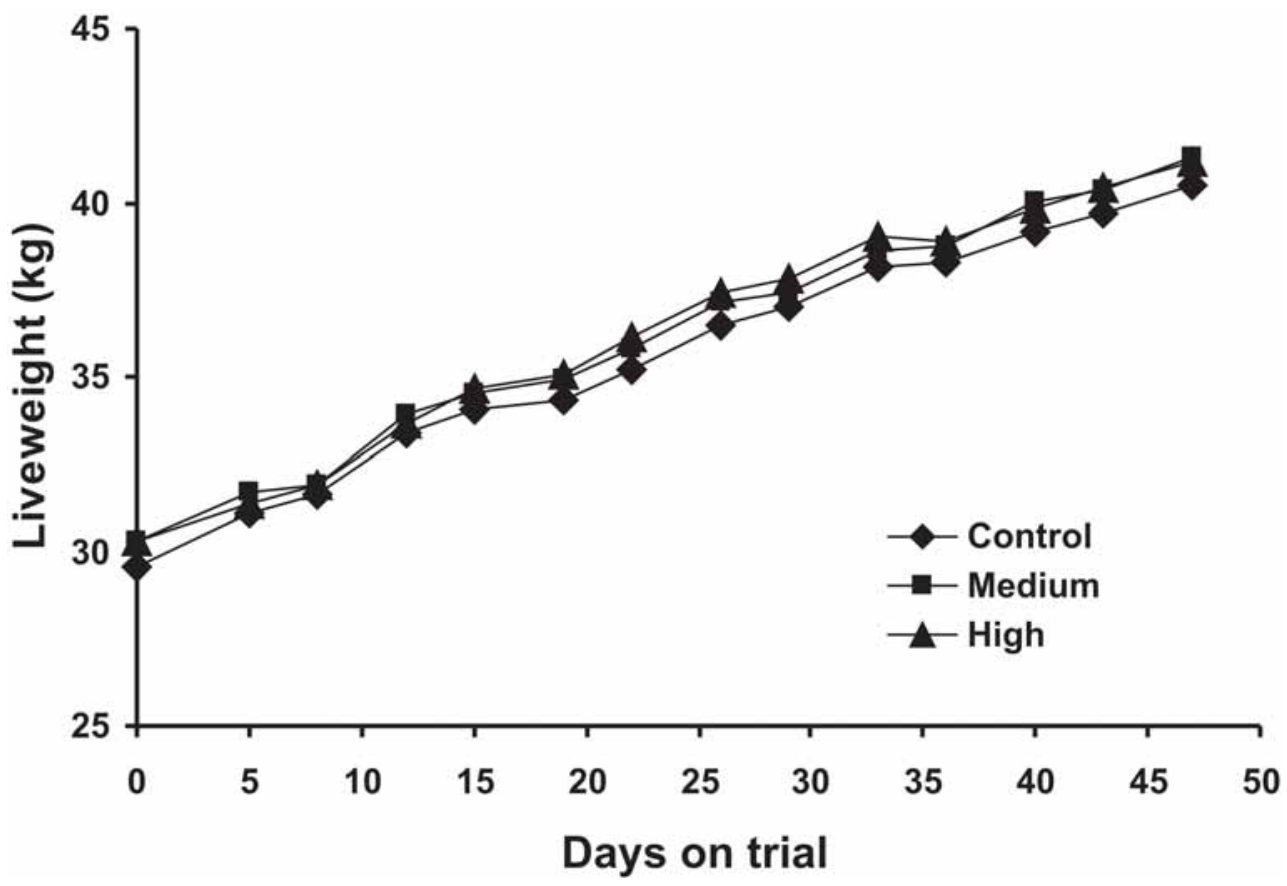

Dry matter intake and feed conversion efficiency

Daily DM intake was 1530, 1450 and $1285 \mathrm{~g} / \mathrm{lamb} /$ day for $\mathrm{C}, \mathrm{M}$ and $\mathrm{H}$ lambs, respectively $(\mathrm{P}=0.07$; Table 1$)$. Feed conversion efficiency was $33 \%$ higher $(\mathrm{P}<0.05)$ for lambs on the high lipid diet $(85 \mathrm{~g}$ carcass gain $/ \mathrm{kg}$ DM intake) compared with the control lambs (64 g carcass gain/kg DM intake).

\section{Fatty acids in lean meat}

There were no effects of dietary lipid concentration on the total concentration of lipid in the raw lean meat but it did affect the composition of the individual fatty acids in the meat (Table 2). The lambs receiving the high dose of oil had significantly lower $(\mathrm{P}<0.05)$ concentrations of total saturated fatty acids compared with lambs receiving the medium dose and had significantly higher $(\mathrm{P}<0.001)$ concentrations of trans-vaccenic acid. The concentration of total mono-unsaturated fatty acids was similar for the medium and high doses, and both were significantly lower than the control. The concentration of $\mathrm{C} 18: 2$, and of $\mathrm{C} 18: 3$ (main constituents of the dosed oil), were significantly higher $(\mathrm{P}<0.001)$ in the $\mathrm{M}$ and $\mathrm{H}$ lambs

Table 2 Adjusted means of the concentration of total fatty acids ( $\mathrm{mg} / \mathrm{g} \mathrm{DM}$ ) and the proportions of individual fatty acids and groups of fatty acids ( $\mathrm{g} / 100 \mathrm{~g}$ total fatty acids) in the meat from the Control group of lambs and the lambs receiving Medium ( $28 \mathrm{ml} /$ day) or High $(56 \mathrm{ml} /$ day $)$ doses of oil.

\begin{tabular}{|c|c|c|c|c|c|}
\hline & \multicolumn{3}{|c|}{ - Treatment } & \multicolumn{2}{|c|}{$\longrightarrow$ Signif. } \\
\hline & Control & Medium & High & SED & $\mathrm{P}$ \\
\hline Total fatty acids & 79.2 & 93.2 & 87.7 & 9.70 & NS \\
\hline Total saturated fatty acids & $44.2^{\mathrm{ab}}$ & $45.2^{\mathrm{a}}$ & $42.7^{b}$ & 0.86 & * \\
\hline Trans vaccenic acid (trans-11 C18:1) & $3.4^{c}$ & $4.3^{\mathrm{b}}$ & $5.5^{\mathrm{a}}$ & 0.33 & *** \\
\hline Total mono-unsaturated fatty acids & $40.6^{\mathrm{a}}$ & $37.8^{\mathrm{b}}$ & $37.7^{\mathrm{b}}$ & 0.86 & *** \\
\hline Cis-9, trans-11 conjugated linoleic acid & 0.8 & 0.9 & 1.0 & 0.08 & NS \\
\hline Linoleic acid (C18:2) & $2.4^{\mathrm{c}}$ & $3.3^{b}$ & $4.4^{\mathrm{a}}$ & 0.39 & *** \\
\hline Linolenic acid (C18:3) & $1.6^{\mathrm{c}}$ & $2.5^{\mathrm{b}}$ & $3.3^{\mathrm{a}}$ & 0.21 & *** \\
\hline Total poly-unsaturated fatty acids & $8.5^{\mathrm{b}}$ & $10.0^{\mathrm{b}}$ & $12.2^{\mathrm{a}}$ & 0.90 & 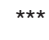 \\
\hline
\end{tabular}

NS not significant, ${ }^{*} \mathrm{P}<0.05$, ${ }^{* *} \mathrm{P}<0.01,{ }^{* * *} \mathrm{P}<0.001$.

Treatment means with different letter superscripts are significantly different from each other. 
Table 3 Adjusted means of the concentration of total fatty acids ( $\mu \mathrm{g} \mathrm{lipid} / \mathrm{ml}$ plasma) and the proportion of individual fatty acids and groups of fatty acids $(\mathrm{g} / 100 \mathrm{~g}$ total fatty acids) in the plasma from the Control group of lambs and the lambs receiving Medium $(28 \mathrm{ml} /$ day $)$ or High $(56 \mathrm{ml} / \mathrm{day})$ doses of oil.

\begin{tabular}{|c|c|c|c|c|c|}
\hline & \multicolumn{3}{|c|}{ Treatment } & \multicolumn{2}{|c|}{ — Signif. } \\
\hline & Control & Medium & High & SED & $\mathrm{P}$ \\
\hline Total fatty acids & $1135^{\mathrm{b}}$ & $1400^{\mathrm{a}}$ & $1524^{a}$ & 114.6 & ** \\
\hline Total saturated fatty acids & $40.2^{\mathrm{a}}$ & $36.7^{\mathrm{b}}$ & $34.9^{\mathrm{b}}$ & 1.10 & *** \\
\hline Trans vaccenic acid (trans-11 C18:1) & $3.1^{\mathrm{b}}$ & $3.1^{\mathrm{b}}$ & $4.8^{\mathrm{a}}$ & 0.33 & 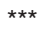 \\
\hline Total mono-unsaturated fatty acids & $29.1^{\mathrm{a}}$ & $22.7^{\mathrm{b}}$ & $22.4^{\mathrm{b}}$ & 0.86 & *** \\
\hline cis 9 , trans-11 conjugated linoleic acid & $1.0^{\mathrm{a}}$ & $0.8^{\mathrm{b}}$ & $0.7^{\mathrm{b}}$ & 0.10 & * \\
\hline Linoleic acid (C18:2) & $6.7^{c}$ & $12.7^{b}$ & $14.2^{\mathrm{a}}$ & 0.71 & *** \\
\hline Linolenic acid (C18:3) & $5.1^{\mathrm{b}}$ & $9.4^{\mathrm{a}}$ & $9.3^{\mathrm{a}}$ & 0.78 & *** \\
\hline Total poly-unsaturated fatty acids & $19.3^{\mathrm{b}}$ & $30.7^{\mathrm{a}}$ & $30.9^{\mathrm{a}}$ & 1.73 & 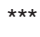 \\
\hline
\end{tabular}

NS not significant, ${ }^{*} \mathrm{P}<0.05,{ }^{* *} \mathrm{P}<0.01,{ }^{* * *} \mathrm{P}<0.001$.

Treatment means with different letter superscripts are significantly different from each other.

than the $\mathrm{C}$ lambs, whereas the concentration of total polyunsaturated fatty acids was higher $(\mathrm{P}<0.001)$ for the high dose of oil than either the medium dose or the control treatment. In most cases the concentrations of individual fatty acids in the lambs receiving the medium dose of oil were intermediate between the controls and the lambs receiving the high dose of oil.

\section{Fatty acids in plasma}

The medium and high doses of oil increased the total lipid content of the plasma by $23 \%$ and $34 \%$, respectively, compared to the control lambs $(\mathrm{P}<0.01$, Table 3$)$. The differences among treatments in the fatty acids composition of the plasma largely mirror the differences found in the meat. The total saturated and monounsaturated fatty acids were higher $(\mathrm{P}<0.001)$ for the control lambs than the lambs drenched with the high dose of oil. The concentration of cis-9 trans-11 CLA was higher $(\mathrm{P}<0.05)$ in the plasma of the control lambs than in the lambs drenched with the high dose of oil. Conversely, trans-vaccenic acid, C18:2, C18:3 and the total poly-unsaturated fatty acids were significantly higher $(\mathrm{P}<0.001)$ in the plasma of lambs receiving the high dose of oil than the control lambs.

\section{Discussion}

The actual dietary total lipid concentrations were $6.3 \%$ and $8.8 \%$ of DM intake for the medium and high levels, respectively, compared with the nominal targets of $6 \%$ and $8 \%$. Lambs tolerated a total lipid concentration of nearly $9 \%$ of DM in a forage diet, with no adverse effects on performance. High levels of dietary lipid, especially poly-unsaturated fatty acids, may suppress populations of rumen protozoa and fungi, fibre digestion in the rumen (Faichney et al. 2002) and DM intake, although the maximum dietary concentration that lambs will tolerate in a forage diet is not well defined. These daily administrations of oil to lambs to simulate changes in lipid composition suggest that breeding and selecting ryegrass to increase the total concentration of fatty acids and modify the profile of individual fatty acids may increase the efficiency of animal production and improve the fatty acid profile in carcass meat for human consumption.

\section{Feed intake, liveweight gain and feed conversion efficiency}

Pasture DM intake was reduced as total lipid concentration in the diet increased, while liveweight gain was not affected. This resulted in higher efficiency of conversion of pasture DM intake to animal product. The higher dietary energy density was expected to translate to higher energy intake and higher liveweight gain. The basis for this expectation is that energy intake is usually sub-optimal for grazing ruminants. However, the comparatively high average daily gain ( $238 \mathrm{~g} /$ day) for all treatments despite their differing energy densities, suggests that energy intake was not the first limiting factor for these lambs grazing high quality, leafy ryegrass during November and December. The lambs were able to trade-off the higher energy density for reduced DM intake. A similar trade-off has been observed in studies simulating changes in other plant constituents such as nitrogen (Cosgrove et al. 1999) or soluble sugars (Cosgrove et al. 2001). Ruminants may however, be constrained by energy intake in other circumstances, such as in summer when ryegrass typically has a lower energy density, or when low availability (e.g. short pasture, low mass or low proportion of green leaf) restricts intake. In any case, a ryegrass selected for greater lipid concentration could increase energy balance and the efficiency of production in pasture-based grazing systems, whether this is achieved by animals requiring less feed to sustain liveweight gain (as in this trial), or by achieving a higher liveweight gain. One proviso to realising benefits from 
selecting for this trait in ryegrass is that the DM yield should be at least as good as current cultivars.

\section{Fatty acids in muscle and plasma}

Linseed and sunflower oils contain high proportions of C18:2 and C18:3, respectively, and the proportions of these fatty acids in the meat and in the plasma increased in the treated lambs compared with the control lambs. This suggests that modifications to ryegrass aimed to change specific, desirable fatty acids can translate to improved product attributes, as observed by adding e.g. linseed to a concentrate-based finishing diet (Raes et al. 2003). The higher concentrations of $\mathrm{C} 18: 2$ and $\mathrm{C} 18: 3$ in lean meat were offset by the reduction in the concentration of the saturated and mono-unsaturated fatty acids (especially of cis-9 C18:1). However, the increase in the proportions of trans-vaccenic acid (and the other isomers of C18:1) in the plasma and the meat suggests that the high-lipid diet may have caused some disruption of the rumen micro flora involved in the bio-hydrogenation of dietary $\mathrm{C} 18: 2$ and $\mathrm{C} 18: 3$. Increasing the dietary intake of $\mathrm{C} 18: 2$ and $\mathrm{C} 18: 3$ by the lambs did not increase the proportions of the longer chain omega- 6 or omega- 3 poly-unsaturated fatty acids in the meat (data not shown) despite $\mathrm{C} 18: 2$ and $\mathrm{C} 18: 3$ being the precursors in tissues for these groups of longer chain fatty acids. The total concentration of fatty acids in the meat did not increase on the high-lipid diets despite a higher concentration in the plasma.

Greater differences in fatty acid composition between treated and control lambs than recorded here may be possible if the treatments were applied for longer than the 6 weeks used in this trial to represent a typical finishing period. For example, in a trial using rumenprotected tuna oil, maximum enhancement of the concentration of poly-unsaturated fatty acids in intramuscular fat occurred in 6 weeks (S.M. Kitessa, CSIRO Livestock Industries pers. comm.), but changes caused by vegetable oils (not rumen-protected) may accrue over a longer period. Although red meats are a comparatively minor source of human dietary fatty acids, the benefits for human health could be enhanced further if the polyunsaturated fatty acids could be increased at the expense of the saturated fatty acids more than the monounsaturated fatty acids (Mir et al. 2003). The organoleptic properties of the meat were not assessed in this trial however vegetable oils at the levels used are not likely to cause adverse effects on eating quality or on shelf life as can occur with fish oils (Vatansever et al. 2000).

\section{Lipids - a new goal for ryegrass breeding?}

The main goal of ryegrass selection in New Zealand has generally been to increase DM yield directly, or indirectly through improvements to pest and disease resistance
(Woodfield 1999), and it is implicit (though seldom tested) that higher yield readily converts to higher animal production. Selecting for traits that improve nutritive value (and feed conversion efficiency) of ryegrass is comparatively rare (see Easton et al. 2002), one example being higher water soluble carbohydrate (WSC) in ryegrasses in the UK (Humphreys 1989). However, there is no clear evidence from evaluation of those ryegrasses that higher WSC per se increases animal production (Lee et al. 2000), whereas other benefits e.g. higher intake, reduced excretion of urinary- $\mathrm{N}$ have been identified (Moorby et al. 2001). As these examples demonstrate, the paradigm above does not necessarily apply when nutritive value is changed, and rigorous testing of an hypothesis before breeding and selection commences (proof-of-concept) can help predict the outcome and save time and money. This is especially important for traits intended to alter product characteristics (e.g. fatty acid concentration and profile) as well as product yield. It would be prudent to verify the results reported here in other seasons and by using alternative methodologies. For example, a still functional reticular groove, even in non-suckling ruminants may result in orally dosed compounds bypassing the rumen (Titchen \& Newhook 1975), and not truly simulate the digestion of those same compounds as constituents of ryegrass. Infusion directly into the rumen would be one way to ensure test substrates are fully exposed to rumen digestion.

\section{Conclusion}

The simulated changes to the total concentration and profile of fatty acids in a ryegrass diet showed that this modification could increase animal productivity and improve product characteristics. These traits could be enhanced in ryegrass or other forage species through conventional or molecular breeding techniques. However, first, the animal responses should be evaluated in other seasons and with other ruminants, especially cattle, to ensure the responses are repeatable and not confined to spring when ryegrass quality is very high. A 'high-lipid' ryegrass may increase liveweight gain or milk production under conditions where animals would be limited by energy intake from conventional ryegrasses. For example, in summer they could gain from both the higher feed conversion efficiency and greater total energy intake associated with the higher dietary energy density. In addition, trials should be conducted with lactating animals to determine whether the proposed dietary modifications cause changes in milk similar to those seen here for intra-muscular fat.

\section{ACKNOWLEDGEMENTS}

This work was funded by the Foundation for Research, 
Science and Technology under contract C10X0203. The assistance of many colleagues with daily dosing of lambs and the cooperation by staff of the Aorangi Research farm is greatly appreciated.

\section{REFERENCES}

Belury, M.A. 1995. Conjugated dienoic linoleate: A polyunsaturated fatty acid with unique chemoprotective properties. Nutrition Reviews 53: 83-89.

Corl, B.A.; Baumgard, L.H.; Dwyer, D.A.; Griinari, J.M.; Phillips, B.S.; Bauman, D.E. 2001. The role of delta 9-desaturase in the production of cis-9, trans-11 CLA. Journal of Nutritional Biochemistry 12: 622630.

Cosgrove, G.P.; Parsons, A.J.;Waghorn, G.C. 1999. Exploring the nutritional basis of diet preference and selection. Proceedings of the New Zealand Grassland Association 61: 175-180.

Cosgrove, G.P.; Parsons, A.J.; Marotti, D.M.; Rutter, S.M.; Chapman, D.F. 2001. Opportunities for enhancing the delivery of novel forage atributes. Proceedings of the New Zealand Society of Animal Production 61: 16-19.

Dewhurst, R.J.; Moorby, J.M.; Danelon, J; Tweed, J.K.S. 2002. Effect of diet forage:concentrate ratio on odd-chain fatty acids in milk from Holstein-Friesian cows. Journal of Dairy Science 85 (S1): 318.

Easton, H.S.; Amyes; J.M.; Cameron, N.E.; Green, R.B.; Kerr, G.A.; Norris, M.G.; Stewart, A.V. 2002. Pasture plant breeding in New Zealand: where to from here? Proceedings of the New Zealand Grassland Association 64: 173- 179.

Faichney, G.J.; Gordon, G.L.R.; Welch, R.J.; Rintoul, A.J. 2002. Effect of dietary free lipid on anaerobic fungi and digestion in the rumen of sheep. Australian Journal of Agricultural Research 53: 519-527.

GenStat 2000. GenStat for Windows. Release 4.2. 5th ed. Oxford, VSN International Ltd.

Humphryes, M.O. 1989. Water soluble carbohydrates in perennial ryegrass breeding. III. Relationships with herbage production, digestibility and crude protein content. Grass and Forage Science 44: 423-430.

Knight, T.W.; Knowles, S.; Death, A.F.; West, J.; Agnew, M.; Morris, C.A.; Purchas, R.W. 2003. Factors affecting the variation in fatty acid concentrations in lean beef from grass-fed cattle in New Zealand and the implications for human health. New Zealand Journal of Agricultural Research 46: 83-95.

Kritchevsky, D. 2000. Antimutagenic and some other effects of conjugated linoleic acid. British Journal of Nutrition 83: 459-465.

Lee, M.R.F.; Jones, E.L.; Moorby, J.M.; Humphrey,
M.O.; Theodorou, M.K.; MacRae, J.C.; Scollan, N.D. 2000. Production responses from lambs grazing on Lolium perenne selected for high water soluble carbohydrate. pp. 45-50. In: Grazing Management. Eds. Rook, A.J.; Penning, P.D. British Grassland Society Occassional Symposium No. 34.

Mir, P. S.; Ivan, M.; He, M. L.; Pink, B.; Okine, E.; Goonewardene, L.; McAllister, T. A.; Weselake, R.; Mir, Z. 2003: Dietary manipulation to increase conjugated linoleic acids and other desirable fatty acids in beef: a review. Canadian Journal of Animal Science 83: 673-685.

Moorby, J.M.; Miller L.A.; Evans, R.T.; Scollan, N.D.; Theodorou, M.K.; MacRae, J.C. 2001. Milk production and $\mathrm{N}$ partitioning in early lactation dairy cows offered perennial ryegrass containing a high concentration of water soluble carbohydrates. Proceedings of the British Society of Animal Science: 6.

Raes, K.; Haak, L.; Balcaen, A.; Claeys, E.; Demeyer, D.; De Smet, S. 2003. Effect of linseed feeding at similar linoleic acid levels on the fatty acid composition of double-muscled Belgian Blue young bulls. Meat Science 66: 307-315.

Salminen, I.; Mutanen, M.; Jauhiainen, M.; Aro, A. 1998. Dietary trans fatty acids increase conjugated linoleic acid levels in human serum. Journal of Nutritional Biochemistry 9: 93-98.

SAS 1990. SAS users guide: statistics. SAS Institute, Cary, NC.

Simopoulos, A.P. 1996. Omega-3 fatty acids Part 1: Metabolic effects of omega-3 fatty acids and essentiality. pp. 51-73. In: Handbook of Lipids in Human Nutrition. Ed. Spiller, G. A. CRC Press, NY.

Titchen, D.A.; Newhook, J.C. 1975. Physiological aspects of suckling and the passage of milk through the ruminant stomach. pp. 15-29. In: Digestion and Metabolism in the ruminant. Eds. I.W. McDonald, I.W.; Warner, A.C.I. Proceedings of the IV International Symposium on Ruminant Physiology. The University of New England Publishing Unit, N.S.W.

Ulbricht, T.L.; Southgate, D.A.T. 1991. Coronary heart disease: seven dietary factors. The Lancet 338: $985-$ 992.

Vatansever, L.; Kurt, E.; Enser, M.; Nute, G. R.; Scollan, N. D.; Wood, J. D.; Richardson, R. I. 2000. Shelf life and eating quality of beef from cattle of different breeds given diets differing in n-3 polyunsaturated fatty acid composition. Animal Science 71: 471-482.

Woodfield, D.R. 1999. Genetic improvements in New Zealand forage cultivars. Proceedings of the New Zealand Grassland Association 61: 3-7. 